Article

\title{
Extended D-TomoSAR Displacement Monitoring for Nanjing (China) City Built Structure Using High-Resolution TerraSAR/TanDEM-X and Cosmo SkyMed SAR Data
}

\author{
Fulong Chen ${ }^{1,2,3}$, Wei Zhou ${ }^{1,2, *}$, Caifen Chen ${ }^{4}$ and Peifeng Ma ${ }^{5}$ \\ 1 Cooperative Innovation Center for Digitalization of Cultural Heritage in Traditional Villages and Towns, \\ Hengyang Normal University, No. 16 HengHua Road, ZhuHui District, Hengyang 421002, China; \\ chenfl@aircas.ac.cn \\ 2 Key Laboratory of Digital Earth Science, Aerospace Information Research Institute, Chinese Academy of \\ Sciences, No. 9 Dengzhuang South Road, Haidian District, Beijing 100094, China \\ 3 Key Laboratory of Earth Observation Hainan Province, Sanya 572029, China \\ 4 Beijing Jucai Zhenbang Enterprise Management Consultant Co., Ltd., Beijing 100038, China; \\ chencaifenhome@sohu.com \\ 5 Institute of Space and Earth Information Science, The Chinese University of Hong Kong, ShaTin, N.T., \\ Hong Kong 999077, China; mapeifeng@cuhk.edu.hk \\ * Correspondence: zhouwei@aircas.ac.cn
}

Received: 30 September 2019; Accepted: 7 November 2019; Published: 9 November 2019

\begin{abstract}
The availability of high-resolution spaceborne synthetic aperture radar (SAR) data coupled with the ongoing refinement of tomographic SAR (TomoSAR) technology has made use of radar data feasible for preventive monitoring and assessment of built structures. In this study, we first applied extended differential TomoSAR (D-TomoSAR) to a set of 26 scenes of TerraSAR/TanDEM-X (TSX/TDX) (2013-2015) and 32 scenes of Cosmo-SkyMed (CSK) (2015-2017) images to estimate motions of skyscrapers, bridges and historical monuments in Nanjing City, China. The calculation and isolation of unknown parameters in the D-TomoSAR model, including linear velocity, thermal dynamics and structural heights, helped to estimate millimetric statistics of motion time series. Then, aforementioned two SAR datasets were tentatively tested using amplitude dispersion and phase stability indicators, highlighting the performance and sensitivity of X-band SAR in structural displacement monitoring. Experimental results demonstrated that motion indexes, e.g., heterogeneities of thermal amplitudes and spatiotemporal displacements, were useful to evaluate the conditions of built structures being monitored, in particular when their structural topology were visible owing to the enhanced density of persistent scatterer (PS) measurements. This study implies the value of high-resolution D-TomoSAR tools in the preventive monitoring and health diagnosis of built structures elsewhere over the world.
\end{abstract}

Keywords: interferometric SAR; motion; built structure; heritage; Nanjing

\section{Introduction}

Acting as economic lifelines, large-scale infrastructures such as expressways, dams and power-lines are playing an increasingly important role in urban and industrial development of nations and societies. These infrastructures have their own operational life-cycles and their stability and efficiency can deteriorate from long-term natural degradations (e.g., material erosion) and transient human-induced geohazards (e.g., land subsidence). In present times sustainability of built heritage sites, that are unique and culturally significant landmarks, and are evidence of society's history and evolution, faces various challenges from an increasingly wide-range of anthropogenic pressures. Consequently, monitoring 
of both historic and modern built structures becomes necessary to prevent damage from unexpected events and to ensure sustainability of social-economic benefits that they provide.

Geodetic methods, such as Global Positioning System (GPS) [1], leveling [2] or deployment of special in-situ sensors [3] have widely been employed for structural monitoring and to assess the health of built structures. However, these conventional methods have several limitations, such as they are labor intensive, expensive and have limited observations in either space or time [4]. Moreover, prior knowledge to make specific point observations, required for problematic areas, is in principal not available [4]. Compared to the geodetic methods, differential synthetic aperture radar (DInSAR), particularly multi-baseline DInSAR (MT-InSAR) has proven to be an effective tool for accurate scattered localization (e.g., within $1 \mathrm{~m}$ in height) and monitoring of deformations (e.g., millimeter level accuracy) [5-8] when multiple phases of temporal SAR acquisitions are analyzed. Availability of high-resolution spaceborne SAR data (1m or better), to create an enhanced spatial dense sets of measuring points, even if distributed vertically, along an individual structure using MT-InSAR, such as persistent scatterer interferometry (PSInSAR) $[9,10]$. Complemented by continuing development of tomographic SAR (TomoSAR) and differential TomoSAR (D-TomoSAR) technologies [11-13], unfavorable layovers on SAR imagery can be mitigated, making D-TomoSAR promising for the risk monitoring of built structures [13-18] in urban landscapes. Owing to the enhancement of persistent scatterer (PS) points by synergistically analyzing phase and amplitude of SAR images at the cost of time consumption [19], risk monitoring of built structures is now even possible using medium resolution SAR data, such as Sentinel-1. Compared with point-based geodetic observations, D-TomoSAR works in a more cost-effective manner by using square-based motion products, such as motion rates and their differential motion trends in space and time. Note that, the extend D-TomoSAR approach [14], is always preferred for the architecture monitoring in the built environment considering the significant kinetic components of thermal dilation from built structures.

In pilot case studies, carried out to demonstrate the capability of X-band high resolution SAR data in structural monitoring, we tested the performance of the two-tier network D-TomoSAR approach [20] to monitor subtle displacements in three typical targets, building, bridge and heritage remains, in the urban landscape of Nanjing city, China. The rest of this paper is organized as follows. The study site and data are described in Section 2, followed by methods in Section 3 and experimental results and analysis in Section 4. Then, the validation of D-TomoSAR results is illustrated, followed by the tentative performance testing of TerraSAR/TanDEM-X (TSX/TDX) and Cosmo-SkyMed (CSK) data in the subtle motion inversion in Section 5. Finally, some conclusions are drawn in Section 6.

\section{Study Site and Data}

As the capital of Jiangsu province and the second largest city in East China (Figure 1), Nanjing has an administrative area of approximately $6600 \mathrm{sq} . \mathrm{km}$ and a total population of 8.33 million. Nanjing has a prominent place in Chinese history and culture, serving as the capital of various Chinese dynasties and kingdoms. In the past ten years, there have been significant changes in the urban landscape of Nanjing, triggered by the rise of skyscrapers and construction of bridges and other large-scale infrastructures. Under the influence of the East Asian monsoon, a humid subtropical climate is prevalent in Nanjing with the average annual precipitation of $1090 \mathrm{~mm}$ and monthly average temperature ranging from $2.7^{\circ} \mathrm{C}$ in January to $28.1^{\circ} \mathrm{C}$ in July.

A total number of 58 TSX/TDX Stripmap and CSK Himage single look complex (SLC) images with Horizontal-Horizontal (HH) polarization were collected, covering Nanjing, China. They included 26 scenes of TSX/TDX images acquired in ascending orbit with a central incidence angle of $37.3^{\circ}$ for the period from May 2013 to February 2015; and 32 scenes of CSK images acquired in descending orbit with a central incidence angle of $34.0^{\circ}$ for the period from January 2015 to December 2017. The ground spatial resolution of both these datasets is approximately $3 \mathrm{~m}$. To assess the capability of high-resolution SAR data to monitor displacement in built targets, three image subsets were selected for processing (Figure 1). These included the Nanjing Municipal Public Security Bureau (NPSB) 
Building, Dashengguan Yangtze River (DYR) Bridge and a section of the Ming Dynasty city wall in the northwest corner of Xuanwu Lake. NPSB is a multi-story tower with a height of $119 \mathrm{~m}$, and has been in place since 2005. Preventive monitoring of this building could provide a successful demonstration of utilizing D-TomoSAR technologies to diagnose the health of built targets. DYR Bridge, is an important component of Beijing-Shanghai High-Speed Railway Line, and crosses the Yangtze River in Nanjing, China. With a total length of $1615 \mathrm{~m}$, the main bridge is a large-span double-arch and composite truss-arch structure. This bridge accommodates six railway tracks, including two tracks for Beijing-Shanghai High-Speed Railway, two tracks for Shanghai-Wuhan-Chengdu High-Speed Railway and double lines of Nanjing Municipal Metro. Preventive monitoring and risking mapping of this bridge is understandably essential for the safe operation of the several railway routes mentioned above. Ming Dynasty city wall is a well-known cultural heritage and symbolizes the prosperity and culture of the city dating back to A.D. 1368-1421. Up to now, approximately $25.1 \mathrm{~km}$ of this linear cultural heritage is well preserved, recognized as the longest surviving city wall in China [15]. Natural erosion coupled with anthropogenic activities (e.g., urbanization) have impacted its sustainable conservation.

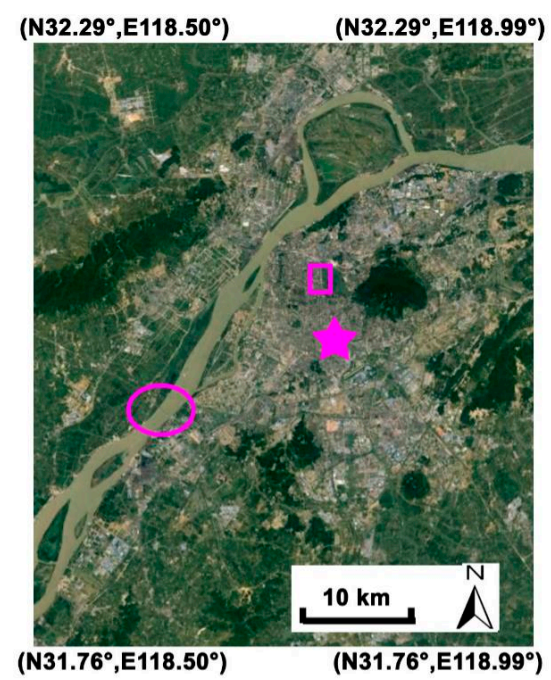

(a)
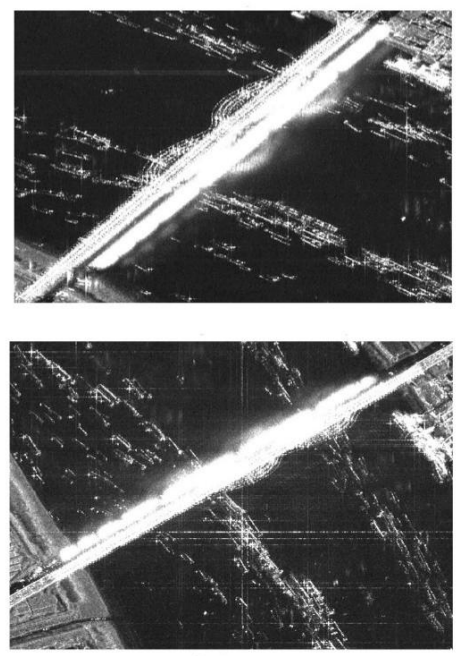

(c)
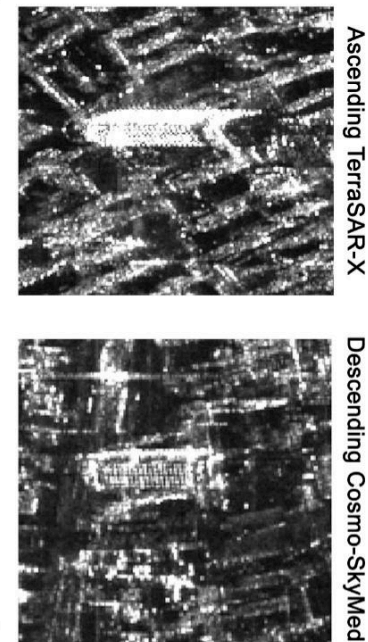

(b)
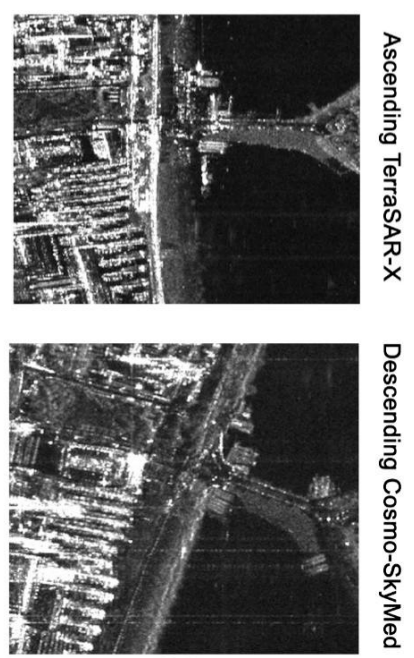

(d)

Figure 1. Location of Nanjing City, China. (a) Representative urban targets on the study site illustrated on temporal-averaged imagery of TSX/TDX and CSK, respectively; (b) NPSB Building alongside of the available GPS observation of "CJDA" in its west with a distance of approximately $420 \mathrm{~m}$, indicated by star in (a); (c) DYR Bridge, indicated by circle in (a); and (d) a section of Ming Dynasty city wall, indicated by rectangle in $(\mathbf{a})$. 
Daily averaged temperature data for SAR acquisitions were also collected and used for the thermal amplitude modelling and calculation (see Table 1). D-TomoSAR data processing were accomplished by the SkySense-InSAR software developed at the Chinese University of Hong Kong (CUHK). Three-arcsecond ( $90 \mathrm{~m}$ ) resolution Digital Elevation Model (DEM) from the Shuttle Radar Topography Mission (SRTM) of the United States Geological Survey (USGS) were used for the geocoding of the D-TomoSAR products by transformation from Range-Doppler SAR imaging coordinates to Universal Transverse Mercator mapping coordinate system. Note that topographic phase contributions were negligible due to the flat terrain of selected subzones. Continuous GPS data for the observation period in 2015 (from the "CJDA" station, west-forward to the NPSB Building with a distance of approximately $420 \mathrm{~m}$, marked by the star in Figure 1) were collected for the quantitative validation of InSAR-derived motions.

Table 1. Interferometric parameters of TSX/TDX and CSK acquisitions accompanied with daily averaged temperature data. Acquisitions of 28 January, 2014 and 20 September, 2016 (indicated by **' symbol) were selected as the reference imagery for the interferogram generation of TSX/TDX and CSK dataset, respectively, to minimize spatial-temporal decorrelation.

\begin{tabular}{|c|c|c|c|c|c|c|c|c|c|}
\hline \multicolumn{5}{|c|}{ TSX/TDX Dataset } & \multicolumn{5}{|c|}{ CSK Dataset } \\
\hline No. & Acquisitions & Sensor & $\begin{array}{c}\text { Bperp } \\
\text { (m) }\end{array}$ & $\begin{array}{c}\text { Temp. } \\
\left({ }^{\circ}\right)\end{array}$ & No. & Acquisitions & Sensor & $\begin{array}{c}\text { Bperp } \\
\text { (m) }\end{array}$ & $\begin{array}{c}\text { Temp. } \\
\left({ }^{\circ}\right)\end{array}$ \\
\hline 1 & 31 May 2013 & TDX & 113.8 & 21 & 1 & 17 January 2015 & CSK2 & 542.3 & 5 \\
\hline 2 & 22 June 2013 & TDX & 303.2 & 27 & 2 & 22 February 2015 & CSK4 & -529.9 & 7 \\
\hline 3 & 14 July 2013 & TDX & 254.6 & 29 & 3 & 22 March 2015 & CSK2 & 232.7 & 12 \\
\hline 4 & 5 August 2013 & TDX & 68.8 & 32 & 4 & 11 April 2015 & CSK4 & -664.5 & 15 \\
\hline 5 & 27 August 2013 & TDX & -103.0 & 28 & 5 & 13 May 2015 & CSK4 & 148.3 & 24 \\
\hline 6 & 18 September 2013 & TDX & 23.0 & 24 & 6 & 14 June 2015 & CSK4 & -746.9 & 27 \\
\hline 7 & 10 October 2013 & TDX & 35.2 & 22 & 7 & 16 July 2015 & CSK 4 & -902.7 & 25 \\
\hline 8 & 1 November 2013 & TDX & -33.1 & 17 & 8 & 17 August 2015 & CSK4 & -384.9 & 27 \\
\hline 9 & 23 November 2013 & TDX & -125.5 & 13 & 9 & 18 September 2015 & CSK4 & -626.3 & 23 \\
\hline 10 & 15 December 2013 & TDX & 0.7 & 8 & 10 & 16 October 2015 & CSK2 & 325.6 & 21 \\
\hline 11 & 6 January 2014 & TDX & -87.2 & 9 & 11 & 17 November 2015 & CSK2 & 194.5 & 13 \\
\hline 12 & 28 January 2014 * & TDX & 0 & 9 & 12 & 19 December 2015 & CSK2 & -164.6 & 5 \\
\hline 13 & 19 February 2014 & TDX & 140.3 & 1 & 13 & 20 January 2016 & CSK2 & -509.4 & 1 \\
\hline 14 & 18 May 2014 & TSX & -49.2 & 20 & 14 & 12 March 2016 & CSK4 & 479.2 & 9 \\
\hline 15 & 9 June 2014 & TDX & 375.9 & 25 & 15 & 13 April 2016 & CSK4 & 191.8 & 21 \\
\hline 16 & 1 July 2014 & TSX & -10.1 & 23 & 16 & 15 May 2016 & CSK4 & 842.2 & 14 \\
\hline 17 & 23 July 2014 & TSX & -219.3 & 31 & 17 & 16 June 2016 & CSK4 & -1166.1 & 25 \\
\hline 18 & 14 August 2014 & TSX & -28.4 & 22 & 18 & 14 July 2016 & CSK2 & 513.8 & 27 \\
\hline 19 & 5 September 2014 & TDX & 127.4 & 25 & 19 & 15 August 2016 & CSK2 & 74.1 & 31 \\
\hline 20 & 27 September 2014 & TDX & 19.8 & 25 & 20 & 20 September $2016^{*}$ & CSK4 & 0 & 22 \\
\hline 21 & 19 October 2014 & TDX & 149.9 & 22 & 21 & 7 November 2016 & CSK 4 & 960.4 & 14 \\
\hline 22 & 10 November 2014 & TDX & 91.4 & 13 & 22 & 9 December 2016 & CSK4 & -612.2 & 9 \\
\hline 23 & 2 December 2014 & TDX & -154.4 & 2 & 23 & 27 February 2017 & CSK4 & 374.3 & 9 \\
\hline 24 & 24 December 2014 & TDX & 195.4 & 6 & 24 & 16 April 2017 & CSK4 & 36.5 & 23 \\
\hline 25 & 15 January 2015 & TSX & -151.5 & 7 & 25 & 18 May 2017 & CSK4 & 137.4 & 24 \\
\hline \multirow[t]{7}{*}{26} & 6 February 2015 & TDX & 76.9 & 4 & 26 & 3 June 2017 & CSK4 & 200.8 & 26 \\
\hline & & & & & 27 & 21 July 2017 & CSK4 & -149.1 & 33 \\
\hline & & & & & 28 & 22 August 2017 & CSK4 & -1519.5 & 30 \\
\hline & & & & & 29 & 19 September 2017 & CSK2 & -754.0 & 25 \\
\hline & & & & & 30 & 5 October 2017 & CSK2 & -903.6 & 14 \\
\hline & & & & & 31 & 10 November 2017 & CSK4 & -1096.4 & 13 \\
\hline & & & & & 32 & 12 December 2017 & CSK 4 & -108.0 & 5 \\
\hline
\end{tabular}

\section{Methods}

\subsection{Rationale and Procedures of the Applied Extended D-TomoSAR}

Although traditional methods are robust and precise based on limited observations through manual leveling or sets of mounted sensors, however, the collected point-like information has the 
disadvantage of providing incomplete motion information. Consequently, in recent years, spaceborne MT-InSAR technologies are increasingly being used to monitor structural health (e.g., bridges [21-24]), in particular owing to the availability of high-resolution SAR datasets.

After the removal of flat-Earth and topographic phases, the phase value of a pixel in the $n$th layer of $N$ co-registered interferometric stacks, for $n=0,1, \cdots, N-1$, can be formulated as:

$$
\left[\varphi_{n}\right]_{2 \pi}=\left(\varphi_{n}\right)_{s}+\left(\varphi_{n}\right)_{d e f}+\left(\varphi_{n}\right)_{\text {APS }+ \text { non_v }}+\left(\varphi_{n}\right)_{\text {noise }}
$$

where [] is the wrapped operator, $\left(\varphi_{n}\right)_{S^{\prime}}\left(\varphi_{n}\right)_{d e f},\left(\varphi_{n}\right)_{A P S+n o n_{-} v}$ and $\left(\varphi_{n}\right)_{\text {noise }}$ are the phase contribution from residual elevation, motion (linear velocity plus material thermal dilation), the combination of atmospheric artifacts and non-linear motions and phase noises, respectively. For a given pixel exhibiting interference scattering from one or more point targets, the mathematical model for the extended D-TomoSAR (space-velocity-temperature) can be formulated as [14]:

$$
\left\{\begin{array}{c}
y_{n}=\iiint_{\substack{\Delta \Delta v \Delta k\\
}} \gamma(s, v, k) \exp \left[-j \varphi_{n}(s, v, k)\right] d s d v d k \\
\text { among them } \varphi_{n}(s, v, k)=2 \pi\left(\eta_{n} v+\zeta_{n} k\right)+2 \pi \varepsilon_{n} s \cong\left(\varphi_{n}\right)_{d e f}+\left(\varphi_{n}\right)_{s}
\end{array}\right.
$$

where $y_{n}$ is the single look complex pixel value in the $n$th layer of interferometric stacks, $\gamma(s, v, k)$ is the target reflectivity profile in the space of $(s, v, k) . \Delta s, \Delta v, \Delta k$ are the range of the expected elevation, linear motion and phase-to-temperature sensitivity value, respectively. $\varepsilon_{n}=2 B_{n} / \lambda R$, $\eta_{n}=2 t_{n} / \lambda, \zeta_{n}=2 T_{n} / \lambda$; and $B_{n}, t_{n}$ and $T_{n}$ are normal, temporal and thermal baselines respectively. $\lambda$ is the wavelength, $R$ is the slant range between target and sensor, and $s$ is the slant elevation (the transformation between vertical height and slant elevation is height $=s \cdot \sin (\theta)$ with the incidence angle $\theta$ ). The standard MT-InSAR approaches using only phase, e.g., persistent scatter interferometry [5] based on the assumption of one single (dominant) scatterer within one pixel, are not able to resolve this interference. Consequently, spectral estimations (e.g., beamforming [25] or the generalized likelihood ratio test [26-28]) need to be applied in the reconstruction of tomography $\gamma(s, v, k)$ using formula (3) by applying the extended D-TomoSAR approach [20]:

$$
\hat{\gamma}(s, v, k)=\max \left(\frac{\left|\boldsymbol{a}(s, v, k)^{H} \boldsymbol{y}\right|}{\|\boldsymbol{a}(s, v, k)\|_{2}\|\boldsymbol{y}\|_{2}}\right) \text { and } \boldsymbol{a}(s, v, k)=\left[\begin{array}{c}
\exp \left(j 2 \pi\left(\varepsilon_{1} s+\eta_{1} v+\zeta_{1} k\right)\right) \\
\ldots \\
\exp \left(j 2 \pi\left(\varepsilon_{N} s+\eta_{N} v+\zeta_{N} k\right)\right)
\end{array}\right]
$$

where $y$ is the complex values of pixels after the differential interferometry, $(\cdot)^{H}$ is the transpose and conjugate operation.

In order to enhance the spatial density of point measurements, in this study, a two-tier network strategy [20] was introduced (Figure 2). In the first Delaunay network, unknown parameters of the linear motion rate, height and thermal amplitude on single persistent scatterer (SPS, indicating as single and dominant scatterer) points were calculated by reconstructing the tomography using formula (3) above. In the second step, double PS (DPS, overlaying PS with double scatterers in layover regions) and the remaining SPS points were further extracted to construct the second-tier local star network referring to single PSs extracted in the first-tier network for the parameter estimation relative to the local reference point of SPSs. Note that, the variable of the atmospheric phase screen (APS) has been assumed to be irrelevant considering the dimension of observed targets (e.g., a length with several hundred meters and the APS within this distance can be assumed spatially homogeneous) as well as to prevent the removal of thermal components that could present a similar spatiotemporal character of APS [21].

Note that, an amplitude dispersion of 0.3 was used for the extraction of SPS candidates; and the temporal coherence value (also denoted the normalized tomographic magnitude, NTM) of 0.72 and 0.70 were respectively applied for the parameter estimation in the first and second-tier networks to 
reconstruct the tomography using formula (3). Simulation results [29] indicated that the standard deviation (so-called accuracy) of motion rates reaches up to $1 \mathrm{~mm} / \mathrm{yr}$ when applying the temporal coherence value of 0.7 along with more than 26 SAR acquisitions. Then, the ratio between the second largest value and the largest value of NTMs on a pixel was calculated for the DPS extraction. That is, if following rules hold simultaneously [20]: (i) the largest value of NTM $<0.7$, (ii) the second one $>0.6$, and (iii) the corresponding ratio $>0.7$; the pixel was determined as a DPS for the second-tier network parameter estimation.

Note that, the applied D-TomoSAR outperforms classical MT-InSAR approaches [5,6] in point target extraction by synergistically analyzing amplitude and phase signature from SAR images, resulting in enhanced spatial density of measurements even prior to the identification of DPSs. Moreover, different from classical MT-InSAR (capable of identifying sinkholes generally), the applied extended D-TomoSAR is more adaptable to monitor structural instability due to its capability to isolate real displacements from material thermal dilations.

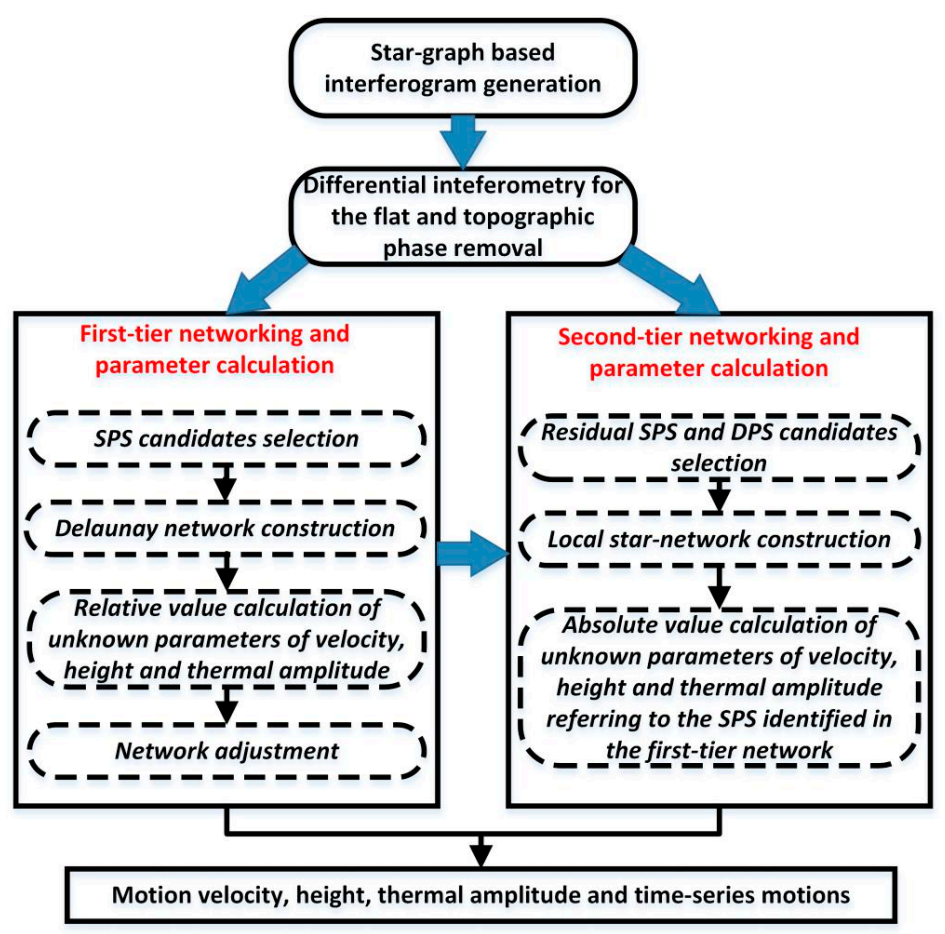

Figure 2. Flow-chart of the applied extend D-TomoSAR in this study.

\subsection{Projection LOS Motions into the Longitudial Direction}

The observed LOS motion $\left(d_{\text {LOS_ } i}, i\right.$ is the sensor platform) of SAR datasets can be projected into the longitudinal direction along built targets using the following formula:

$$
d=\frac{d_{L O S \_i} i}{\sin _{\theta_{\text {inc } \_i}} \cdot \cos _{\alpha_{h o r_{\_} i}}}
$$

where $\theta_{\text {inc } \_i}$ is the incidence angle of SAR data acquisitions, and $\alpha_{\text {hor } \_i}$ is the horizontal angle between the real motion $(d)$ along the longitudinal direction and the satellite LOS direction.

\section{Experimental Results and Analysis}

Following are the performance results of the two-tier network D-TomoSAR approach in monitoring structural instability and health diagnosis of the three selected targets in the built environment of Nanjing City, China. 


\subsection{NPSB Building}

As a representative case on the evaluation of vulnerability of towers and/or skyscrapers, the extended D-TomoSAR derived motion trends along with the thermal-dynamics of the NPSB Building using TSX/TDX and CSK were first analyzed, as illustrated in Figure 3. Due to the high-resolution of SAR data and the resolved parameters (e.g., the estimated height of the building is $106.0 \mathrm{~m}$ for the TSX/TDX and $106.7 \mathrm{~m}$ for the CSK, respectively; with a difference smaller than $1.0 \mathrm{~m}$ ), plenty of PS points (that is, 1011 PSs for TSX/TDX and 695 PSs for CSK) along the facade facing to the line of sight (LOS) direction were extracted (Figure 3a,b), forming the outline of the building in the merged geocoded D-TomoSAR products (with geo-referenced information of motions and corrected heights) from ascending TSX/TDX and descending CSK data (Figure 3c). No PSs were extracted for the top section of the building, comparing the estimated heights with the actual value of $119 \mathrm{~m}$, interpreted from the lack of structure layout in this section generating strong backscatters, e.g., dihedral backscatters with PSs performance. The estimated motion rates from two datasets, primarily in the range of $-2.0 \mathrm{~mm} / \mathrm{yr}$ to $+2.0 \mathrm{~mm} / \mathrm{yr}$, indicated that the building was stable during the observation span of 2013-2017 covering the two X-band SAR images acquired. However, several uplift PSs were detected in the TSX/TDX result, as marked by the pink ellipse in Figure 3a, which could be induced by the facility maintenance on the lobby rooftop. The calculated thermal amplitudes (Figure 3c), primarily in the range of $-0.5 \mathrm{~mm} /{ }^{\circ} \mathrm{C}$ to $+0.5 \mathrm{~mm} /{ }^{\circ} \mathrm{C}$ of TSX/TDX versus $-0.9 \mathrm{~mm} /{ }^{\circ} \mathrm{C}$ to $+0.9 \mathrm{~mm} /{ }^{\circ} \mathrm{C}$ for CSK, indicates that the heat dilation and cold contraction of reinforced concrete structure of the building is evident. It is clear that there is a difference of measured thermal amplitudes from the two datasets. Thermal amplitude, a property of materials which measures the fractional change in length per degree of temperature change [14], should theoretically remain unchanged. The measured inconsistency can be induced by the deficiency of the temporal span of TSX/TDX acquisitions, that is one year and seven months (approximately 1.6 years), resulting in the ambiguity in the estimation of the linear velocity and thermal amplitude jointly controlled by the temporal distribution and periodic temperatures. In addition, the performance of the applied extended D-TomoSAR approach in the extraction of DPSs were quantitatively assessed, as illustrated in Figure 3d. Sixty DPSs were totally identified overlaid on the NPSB Building using TSX/TDX data, accounting for 5.9\% of total measurements. It is clear that the identified DPSs were primarily located at the bottom (with height values ranging from $0 \mathrm{~m}$ to $46 \mathrm{~m}$ ) and the top (with height values from $80 \mathrm{~m}$ to $107 \mathrm{~m}$ ) sections of the building, evident of the double overlaid scatterers in those two layover components.

Generally, the precision of the estimated parameters (motion, height and thermal dilation) depends on the spatial, temporal and thermal baseline tubes of the two SAR systems [14,28]; that is, the lower the correlation between them the better is the estimation [30]. Figure 4 illustrated the spatial/temporal and temperature/temporal grids of the applied two SAR acquisitions. It is clear that the correlation between the three baseline vectors decreases as the increase of the temporal span. Following that, the correlation analysis was carried out for the estimated parameters associated with linear velocity and thermal amplitude (Figure 5), producing small values of $R^{2}$ (goodness of Fit) -0.143 of TSX/TDX and 0.017 of CSK respectively-and the low auto-correlation to avoid the coupled ambiguity in the estimation of two unknown parameters. The result demonstrated that a more reliable thermal amplitude can be derived using the CSK owing to the applied longer temporal span (e.g., approximately 3-year of CSK versus 1.6-year of TSX/TDX) and the resultant lower auto-correlation value (0.017 of CSK versus 0.143 of the other) in the unknown parameter calculation.

Assuming that the thermal expansion is vertical [20] and considering that the incidence angle of CSK SAR data was $34^{\circ}$, a coefficient of linear thermal expansion of the building (with the estimated height of $106.7 \mathrm{~m}$ and the maximum thermal amplitude of $+0.9 \mathrm{~mm} /{ }^{\circ} \mathrm{C}$ ) was calculated which was approximately $10.24 \times 10^{-6} /{ }^{\circ} \mathrm{C}$, a typical value for concrete and steel structures [30]. This again verifies the reliability of the thermal amplitude calculated from CSK. The maximum thermal dilation of this building was approaching $3 \mathrm{~cm}$ calculated by multiplying the maximum thermal amplitude by the temperature span. Considering the stable condition of the structure, the thermodynamics of the 
building were prominent, in particular for the top section due to the accumulative effect, as shown by the motion of the time series (the summed contributions from linear velocity, thermodynamics and non-linear movements) of PSs (Figure 6a,b) which are highly-correlated with the seasonal variation of contemporary temperature data.

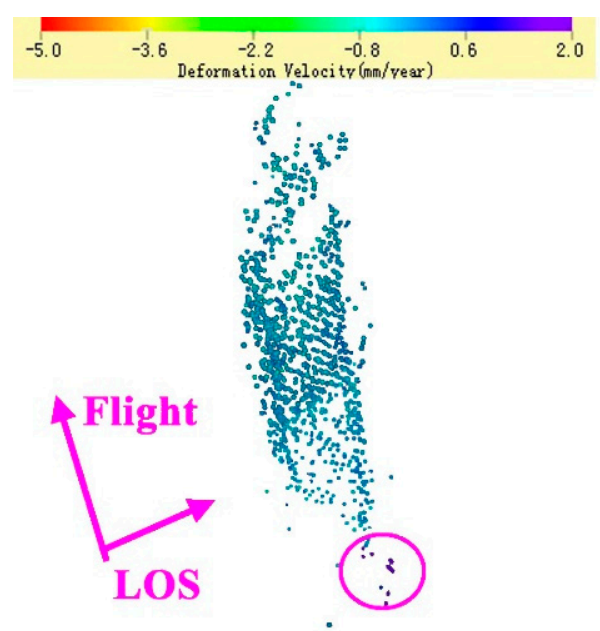

(a)

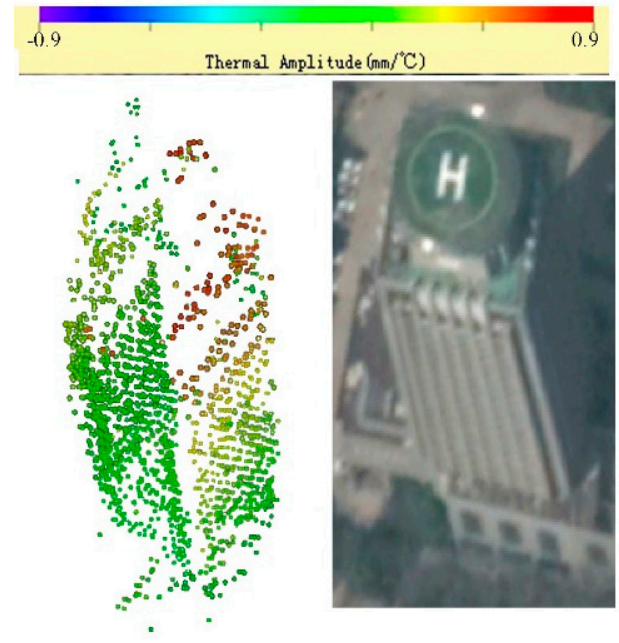

(c)

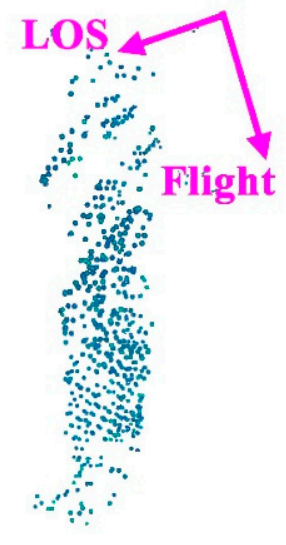

(b)

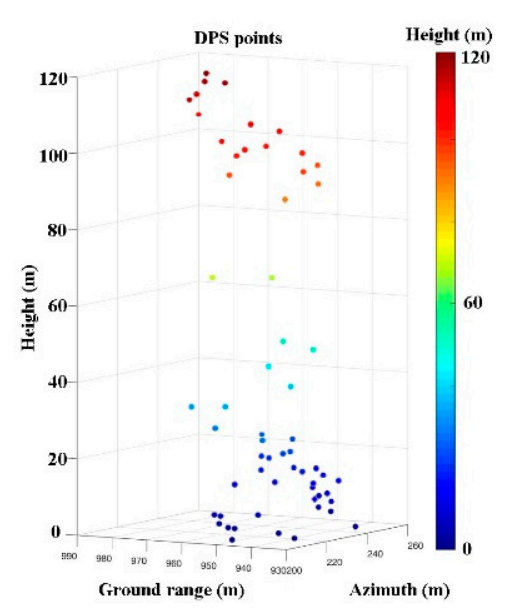

(d)

Figure 3. Estimated motion and thermodynamics parameters of TSX/TDX and CSK data using the extended D-TomoSAR approach along the NPSB Building. $(\mathbf{a}, \mathbf{b})$ are estimated linear motion rates of TSX/TDX and CSK, respectively; (c) is the merged thermal amplitudes calculated from two datasets (the left from TSX/TDX and alternatively the right from CSK) along with the topology of the building reflected on the optical remotely sensed imagery (courtesy of Google Earth) and (d) is the identified DPSs using TSX/TDX. 

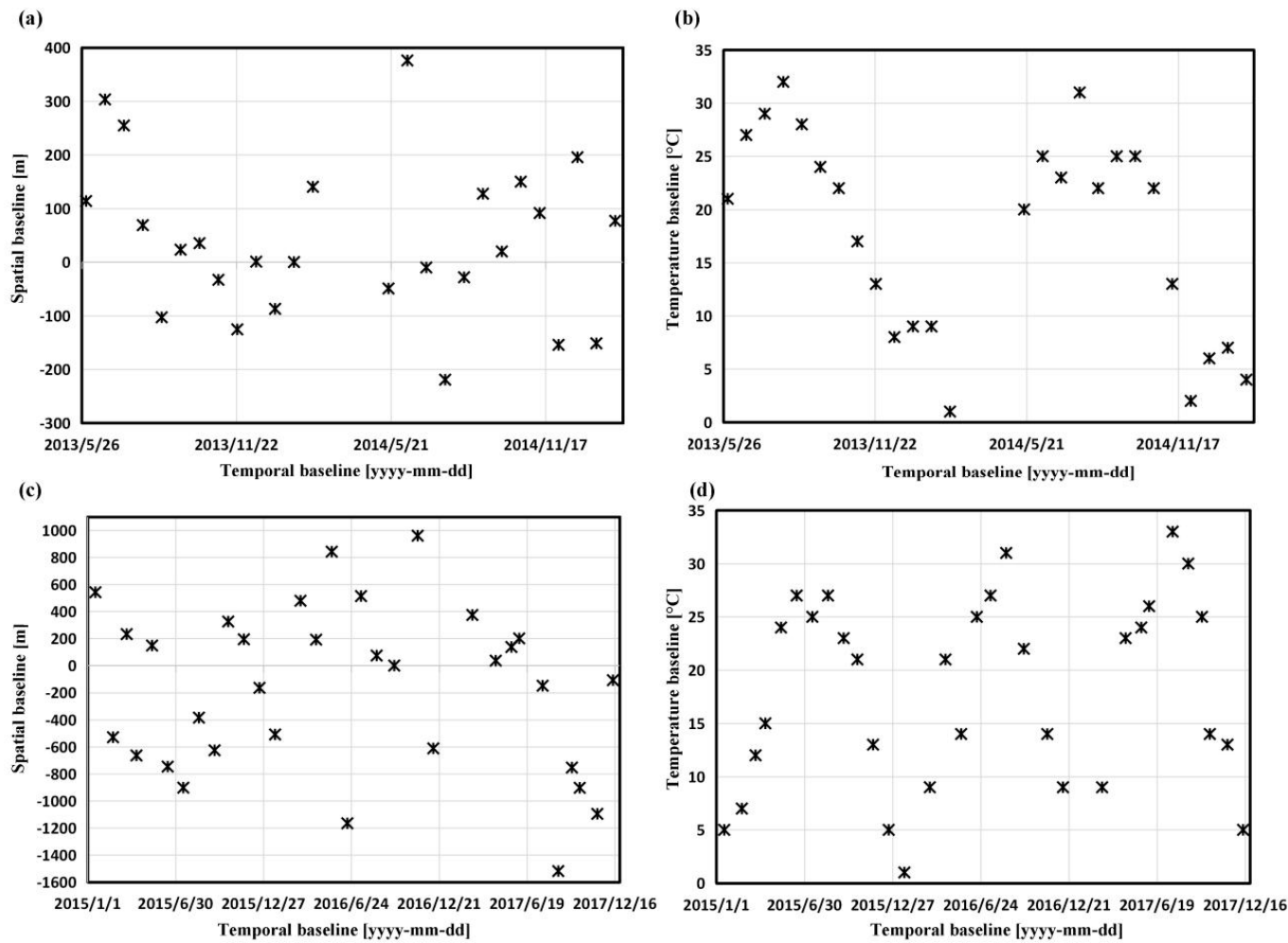

Figure 4. Spatial/temporal and temperature/temporal grids of two SAR datasets applied in this study. $(\mathbf{a}, \mathbf{b})$ TSX/TDX, and (c,d) CSK.
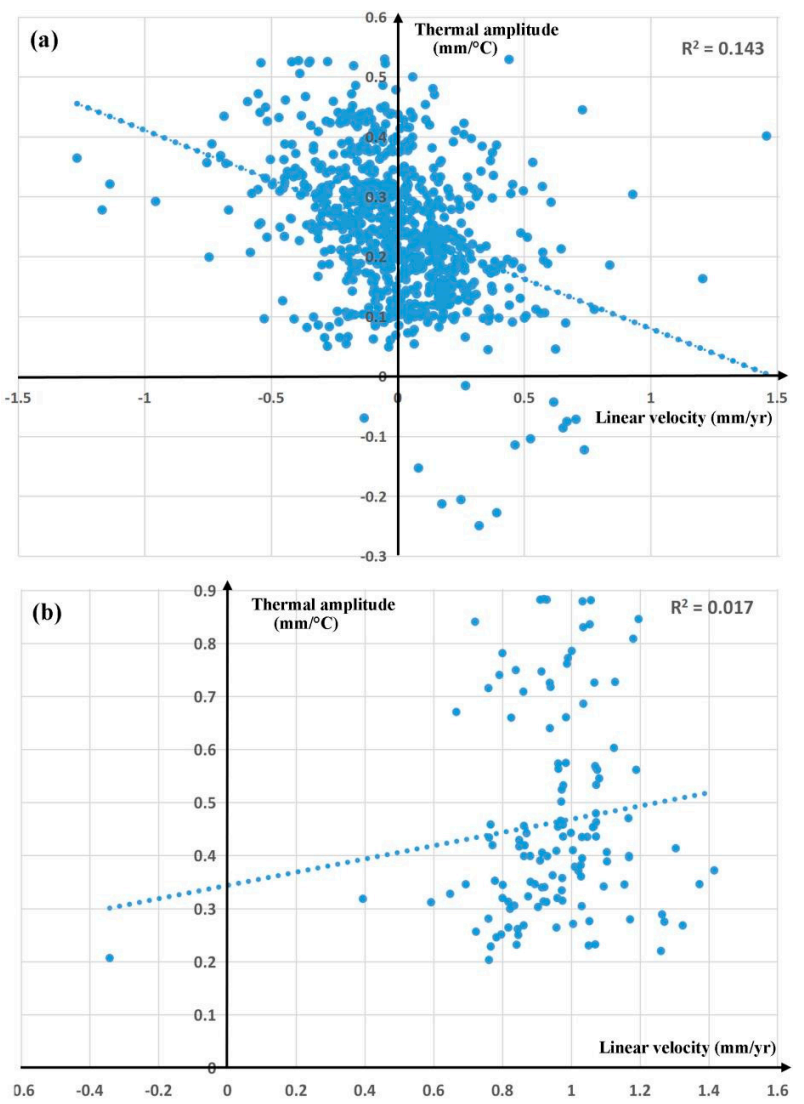

Figure 5. Linear correlation analysis of the estimated parameters of linear velocity and thermal amplitude from the NPSB Building. (a) TSX/TDX and (b) CSK. 

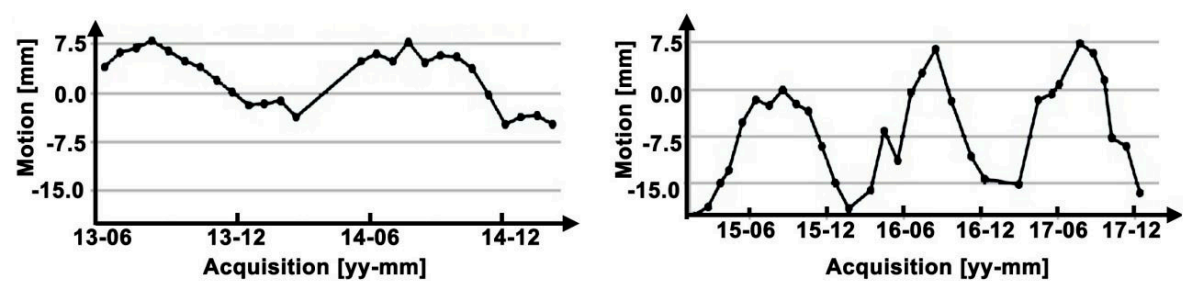

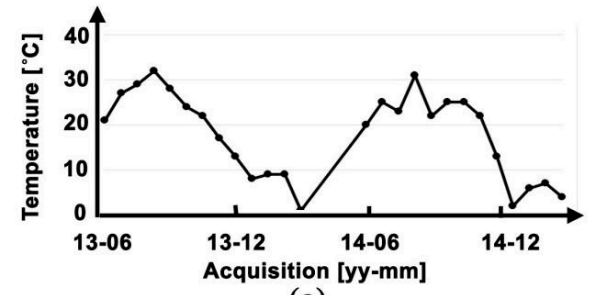

(a)

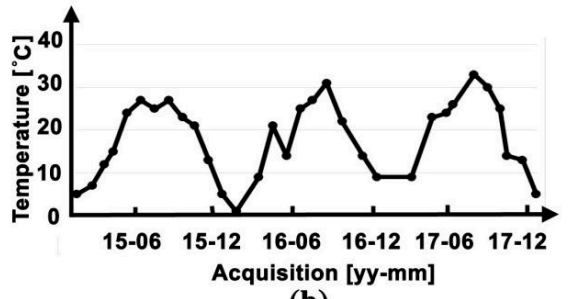

(b)

Figure 6. Motion time series (above) accompanied with temperatures (bottom) of the two datasets in the NPSB Building case. (a) TSX/TDX and (b) CSK, respectively.

\subsection{DYR Bridge}

Displacement products, such as motion velocities and time series and thermodynamics of steel structures on the BYR Bridge, were simultaneously calculated (see Figure 7). Totally, 16,549 PS points and 1962 PS points were detected along the steel bridge by using TSX/TDX and CSK, respectively. The 3-dimensional spatial distribution of PS points overlaid on the architecture is evident, resulting in the observed topology of double-arches (Figure 7), particularly in the TSX/TDX results. It is clear that high-resolution SAR data are beneficial to monitor infrastructure at pinpoint anomalies in structural motion owing to the enhanced PS detected overlaid on the infrastructure; for instance 16,549 PSs of TSX/TDX in this study versus approximately 900 PSs of Sentinel-1 [23]. Generally, all the points belonging to the same part of the bridge overlaid on Piers 4 to 10 move with a uniform and stable trend, primarily with velocity values in the range of $-2.0 \mathrm{~mm} / \mathrm{yr}$ to $+2.0 \mathrm{~mm} / \mathrm{yr}$ in the LOS direction of TSX/TDX and CSK SAR data. Consistent with Sentinel-1 results [23], no PSs remained in two SAR datasets using the temporal coherence threshold for the west-side section of Pier 4 based on the reference point overlaid on middle Pier 7, probably due to the different architecture or applied materials, indicating a structural motion heterogeneity compared with the observed bridge section. Small sinking trends in the LOS direction of two datasets, with values approximately of $-2 \mathrm{~mm} / \mathrm{yr}$ were also detected on the top two arches (particularly in the TSX/TDX result). The motion trend could be triggered from the stress of chords connecting the arch and the bottom deck and due to the heavy-load of passing trains as well as the weight of the steel deck. For long-term safety, such motion anomaly $(-2 \mathrm{~mm} / \mathrm{yr})$ in the form of the spatial heterogeneity compared with surrounding PS measurements needs to be continuously monitored for validating the stability of the bridge. Apart from the motion anomaly on two arches, progressive longitudinal motion trends were also detected; that is, a LOS uplift-sinking trend in approximately W-E direction in ascending TSX/TDX and a reverse trend in descending CSK result. Supported by the pier foundations that reach the bedrock, the vertical motion trends of the rigid bridge structure can be ignored. Thus the detected motion trends in the longitudinal direction (Figure $7 \mathrm{a}, \mathrm{b}$ ) can be attributed to the residual dilation movement along the bridge structure expanding from the reference point overlaid on the middle pier (as marked by the pink cross in Figure 7a,b), apart from the estimated thermodynamics (Figure 7c). This motion pattern was more evident in the TSX/TDX result with a shorter temporal-span (Figure 7a) because of the induced ambiguity in the estimation of the coupled parameters of velocity and thermal amplitude (Figure 5). In summary, the evident sinking on the top two arches as well as longitudinal deformation trend along the BYR Bridge in TSX/TDX results were caused by the underestimation of thermal amplitudes due to the applied shorter temporal-span of 1.6 years. Moreover, for the structural section ranging from Pier 4 
to Pier 6, a motion difference with a statistical value of $1 \mathrm{~mm} / \mathrm{yr}$ between the ascending and descending directions of the bridge were also observed in TSX/TDX result, as illustrated in Figure 8. Although this motion difference is subtle (high probability related to phase artifacts considering the amplitude is close to the precision of D-TomoSAR motion products), its monitoring needs to be prioritized due to the probable occurrence of a tilting motion trend in this section. This motion anomaly was not observed in the following observation period of CSK (Figure 8). Referring to the geometry of SAR imaging and the direction of the bridge (Figure 9), the dilation contribution of the bridge (referring to the middle pier) is indicated as a LOS uplift in the west and a LOS sinking in the east for the TSX/TDX result, and vice versa for the CSK, respectively.

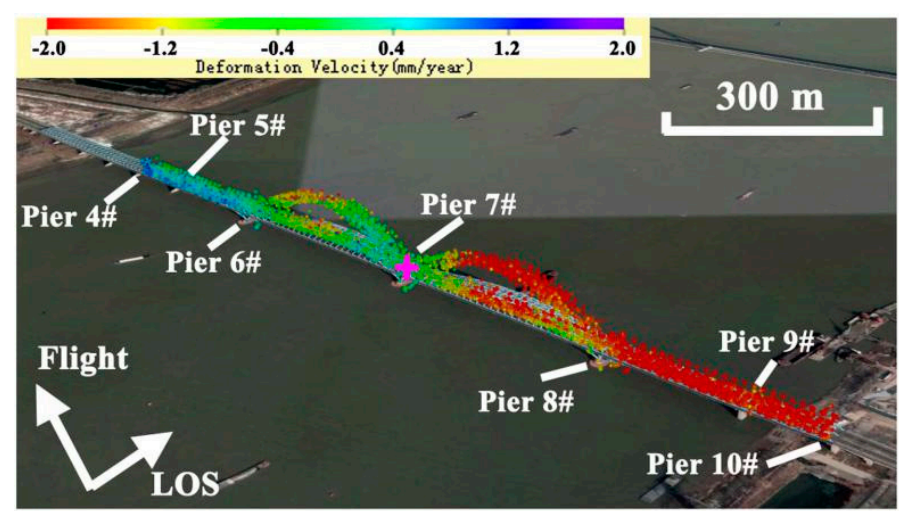

(a)

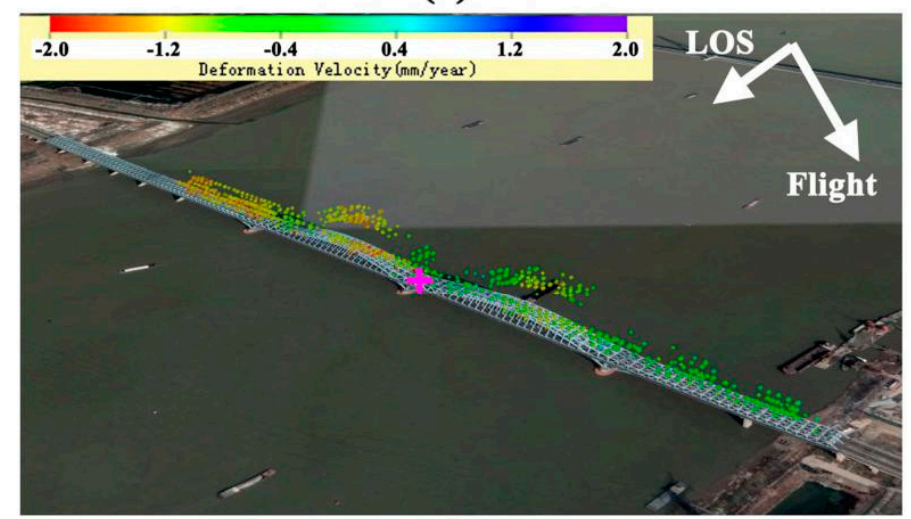

(b)

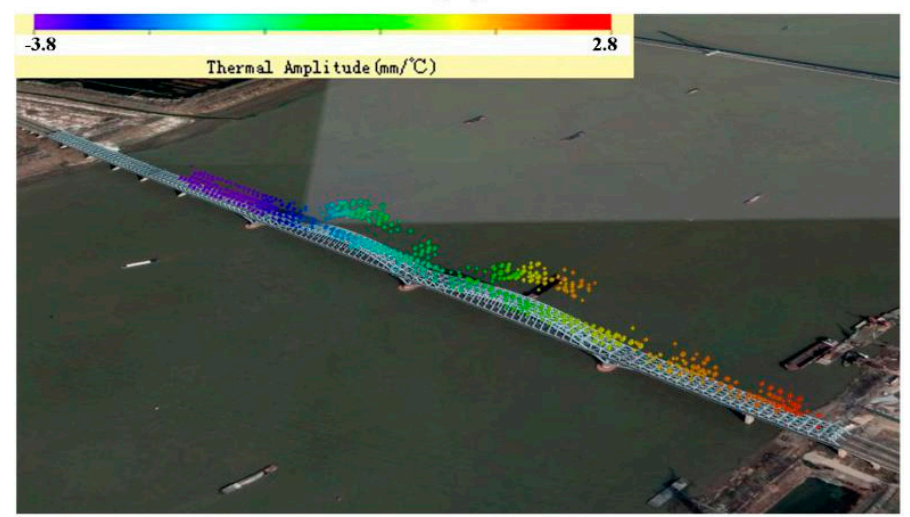

(c)

Figure 7. Extended D-TomoSAR derived motion and thermodynamics parameters on the DYR Bridge (courtesy of Google Earth) based on the selected reference point overlaid on the Pier 7, as marked by the pink cross. (a) Motion velocities estimated from TSX/TDX, (b) motion velocities and (c) thermal amplitudes estimated from CSK data. 

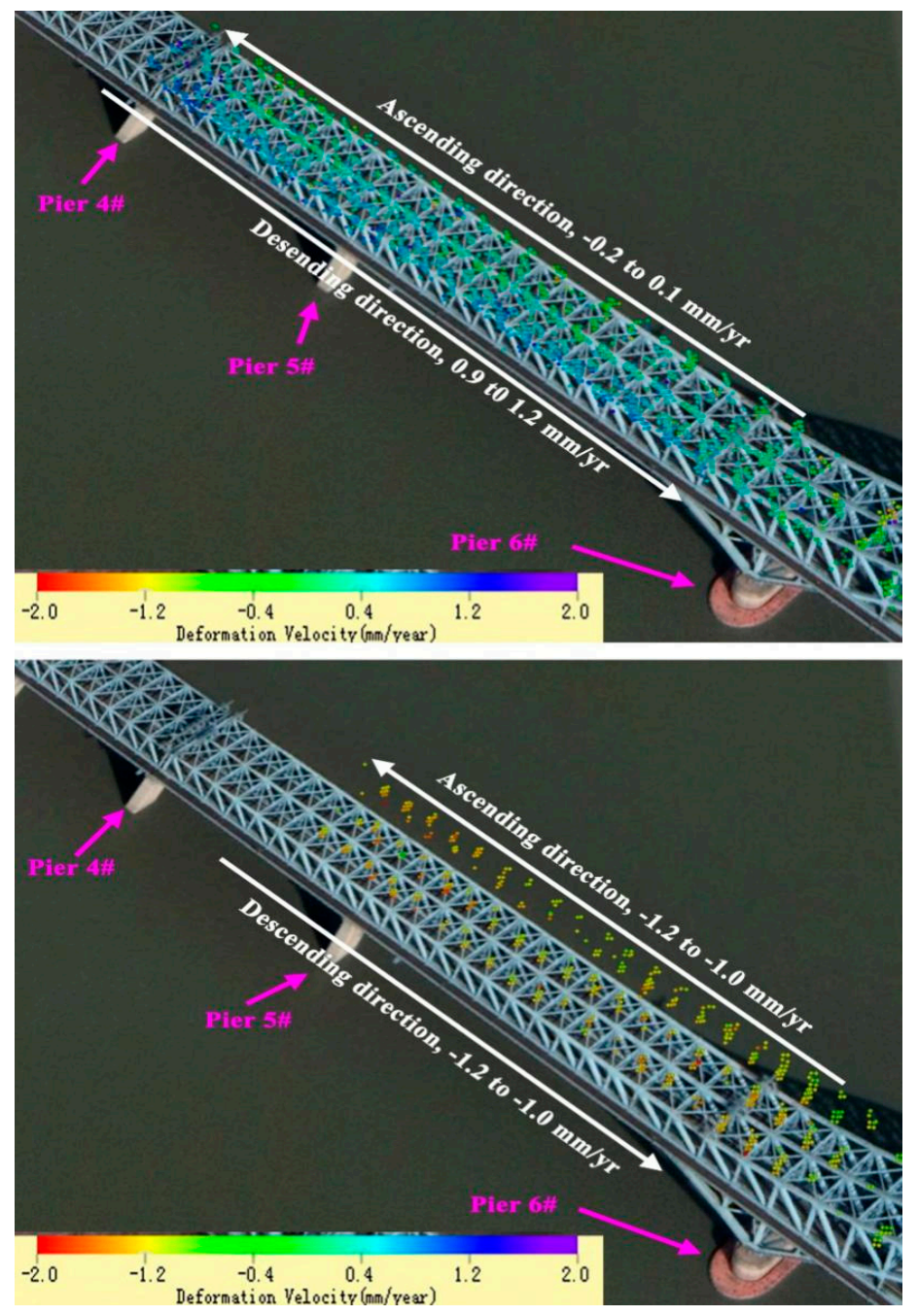

Figure 8. Detected probable occurrence of a titling motion trend in the section ranging from Pier 4 to Pier 6 in the TSX/TDX result in the period from 2013-2015 (top), which no longer existed in the CSK observation period from 2015 to 2017 (bottom).

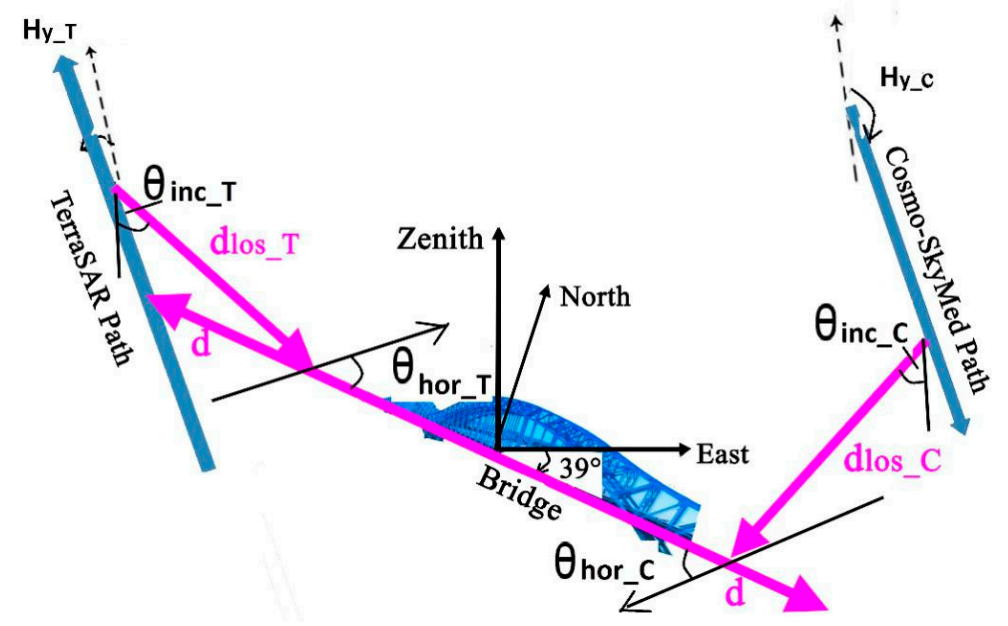

Figure 9. Relationship between detected movements in SAR look directions and the direction of real movements along the longitudinal direction of the DYR bridge. 
The seasonal thermodynamic components of this steel structure can be precisely estimated, in particular using the 3-year CSK SAR acquisitions. Generally, the measured thermal amplitudes for TSX/TDX and CSK LOS observations indicate a converse mode due to corresponding ascending and descending acquisition modes. Using formula (4), the real thermal dilations (d) along the longitudinal direction can be calculated. The absolute heading angle of TSX/TDX $\left(H_{y_{-} T}\right)$ and CSK $\left(H_{y_{-} C}\right)$ is consistent, equaling to $10^{\circ}$, resulting in the uniform horizontal angle of $49^{\circ}$ (for $\alpha_{h o r_{-} T}$ TSX/TDX and for $\alpha_{h o r_{-} C}$ CSK) between the motion in the longitudinal direction and satellite LOS directions ( for $d_{\text {LOS_T }}$ TSX/TDX and for $d_{\text {LOS_C }}$ CSK), where the bridge direction referring to the East is $39^{\circ}$ (Figure 9). Consequently, the real thermal amplitude in the longitudinal direction was $-8.7 \mathrm{~mm} /{ }^{\circ} \mathrm{C}$ to $6.4 \mathrm{~mm} /{ }^{\circ} \mathrm{C}$ using the CSK data with the incidence angle $\left(\theta_{\text {inc_C }}\right)$ of $34^{\circ}$. The calculated linear thermal expansion coefficient of the measured $1272 \mathrm{~m}$ bridge is $11.87 \times 10^{-6} /{ }^{\circ} \mathrm{C}$, which is consistent with the measured values of $11.26 \times$ $10^{-6} /{ }^{\circ} \mathrm{C}$ and $11.19 \times 10^{-6} /{ }^{\circ} \mathrm{C}$ using C-band Sentinel- 1 data [23]. Nonetheless, the measured value is much closer to the physical value of $13.0 \times 10^{-6} /{ }^{\circ} \mathrm{C}$, presented by the relative error of $8.7 \%$ (better than $13-14 \%$ in [23]), implying that the better performance of X-band SAR data in infrastructure monitoring is likely due to its sensitivity to subtle deformations. The result indicated that only the monolithic thermal expansion of the bridge does exist (Figure 7c), suggesting that the entire structure is stable and performs as a rigid-body, avoiding differential motion trends among components of the infrastructure.

In order to pinpoint the trend in physical structural instability, the natural thermodynamic contribution was calculated and then subtracted from the motion time series (the summation of linear velocity, thermodynamics and non-linear movements). Note that, although the thermal estimation of TSX/TDX is not highly accurate, however, the majority of thermal contribution can also be calculated and then be isolated from other motion components, as illustrated in Figure 10, to compare it with the motion time series on representative PSs overlaid on Pier 5 to 9 (PS points overlaid on the same structural component instead of the same PS points detected with the two datasets) with and without thermal contributions derived from TSX/TDX (Figure 10a,b) and CSK data (Figure 10c,d). First, the periodic thermal dilation and cooling contraction of the bridge structure referring to Pier 7 is evident. When the thermodynamics contribution was removed, real motions in LOS direction overlaid on those selected piers were extracted. In general, the variation of real motions on PSs increases as their distance were gradually away from the reference point overlaid on the Pier 7, obeying the error accumulation rule of surveying. The real motions detected in LOS, either due to the bridge structural tilting or subsidence, were utilized as quantitative indicators to evaluate the health conditions of the bridge. The $1-\alpha$ confidence interval for the real motion variation can be $\pm t_{\text {crit }} \cdot s t d e v$, where $t_{\text {crit }}$ is the critical value of the $t$ distribution with degree of freedom $M-1$ ( $M$ is the number of SAR acquisitions) and with significance level of $\alpha / 2$ [22], and stdev is the standard deviation of real motions. Then, the upper and lower limit of real motion variations were defined $( \pm 9.2 \mathrm{~mm}$ for TSX/TDX and $\pm 8.2 \mathrm{~mm}$ for CSK), as highlighted by the dotted-red line in Figure 10b,d. Results indicated that the occurrence of motion anomaly of TSX/TDX and CSK measurements were 3.8\% (5/130) and 5.0\% (8/160), respectively, requiring careful monitoring and analysis. Note that, more intense motion variations of TSX/TDX can be induced by the underestimation of the thermal component. 

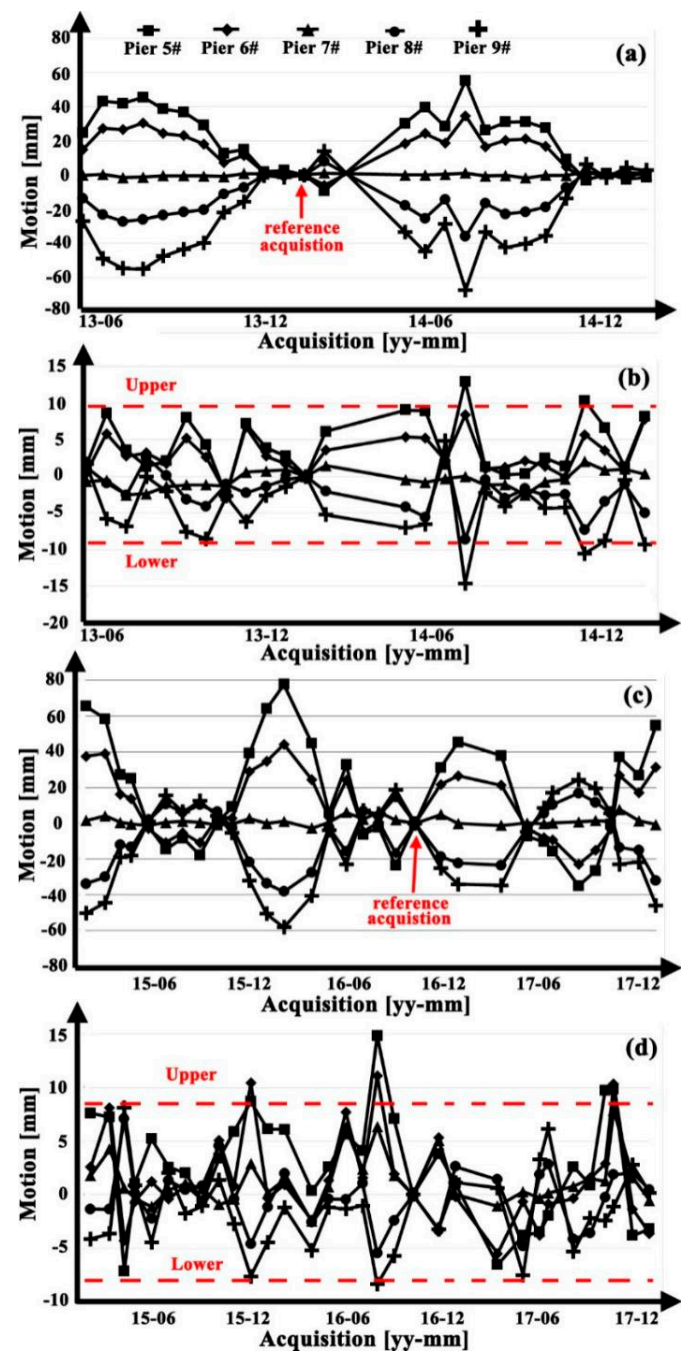

Figure 10. Comparison of motion time series on representative PSs overlaid on Pier 5 to 9 with and without thermal contributions; (a-d) correspond to the TSX/TDX and CSK results, respectively. The reference acquisition of TSX/TDX and CSK data is marked by the red arrow in $(\mathbf{a}, \mathbf{c})$, respectively.

\subsection{Ming Dynasty City Wall}

Based on our previous investigation [15], the extended D-TomoSAR approach was applied using new acquisitions of CSK in 2015-2017 to check the problematic section of the wall section identified by the 2013-2015 TSX/TDX acquisitions, as illustrated in Figure 11; that is, 2863 PSs (approximately 130 PSs per hundred meters) of TSX/TDX observations versus 706 PSs (approximately 32 PSs per hundred meters) of the CSK observations. LOS measurements of two SAR datasets have been projected into vertical direction assuming other motion contributions to be negligible. The motion anomaly along the $180 \mathrm{~m}$ wall section (marked by the interval of pink ellipses in Figure 11a in the TSX/TDX result) was no longer existent in the observation period of CSK from 2015-2017 (Figure 11b), implying the provisional impact of anthropogenic behaviors (e.g., demolition and construction activities; please refer to [15] for more details) on the stability of wall monuments. Motion time series of a representative PS (Figure 11c) also indicated an uplift LOS motion trend was prominent in 2014 with an estimated annual motion rate of $+7.3 \mathrm{~mm} / \mathrm{yr}$ by TSX/TDX data, then gradually shifting into a stable condition $(-0.7 \mathrm{~mm} / \mathrm{yr})$ as estimated by CSK data. Nonetheless, in the second half year of 2017, a mild-median sinking trend was detectable using the PS motion time series (marked by the double-headed arrow in Figure 11c), which needs to be further investigated using new acquisitions of SAR data or other geotechnical tools. 

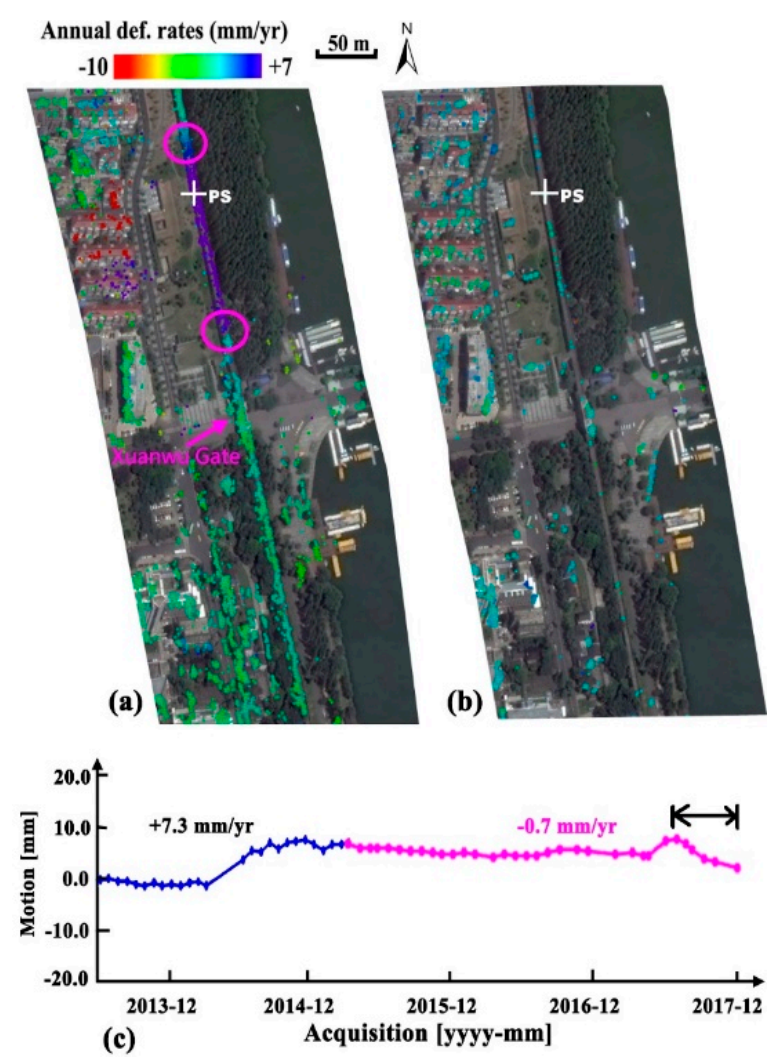

Figure 11. Motion time series analysis of the section of Xuanwu Gate of the Ming Dynasty city wall. Annual motion rates derived from TSX/TDX (a) and CSK (b); (c) motion time series on a representative PS (marked by the white cross in $(\mathbf{a}, \mathbf{b})$ ), including TSX/TDX observations marked in blue and CSK observations marked in pink.

\section{Validation and Discussions}

\subsection{Validation}

In order to verify the accuracy of parameters (particularly for motion estimates), the D-TomoSAR (the extension of PSInSAR by synergistically analyzing phase and amplitude of SAR images for the enhancement of SPS measurements apart from the additional gain from the detection of DPSs) $[19,20,31]$ derived results were quantitatively validated. First by considering the concurrence inversion of motion and heights, the validity of height estimates (e.g., the comparison of estimated values with actual heights of built elements) can, to some extent, validate the estimates of motions (deformation velocities and thermodynamic components) [16]. For instance, the double-arch architecture of DYR Bridge is evident in the D-TomoSAR result. The measured height on the top of the arch referring to the deck is approximately $67 \mathrm{~m}$ that is consistent with the actual value of $68 \mathrm{~m}$, indicating the good vertical geolocation (1 $\mathrm{m}$ or even better) of PSInSAR $[9,10]$ and its extension technologies such as D-TomoSAR applied in this study. In addition, the performance of applied D-TomoSAR in scatterer localization was again verified by the measured height difference of NPSB Building, that is $0.7 \mathrm{~m}$, calculated from two sensors of SAR data with different imaging geometries and observation tubes. Second, the calculated linear thermal expansion coefficients [30] of the NPSB Building and DYR Bridge were applied to assess the robustness and accuracy of D-TomoSAR result. For example, the corresponding value on the NPSB Building of $10.24 \times 10^{-6} /{ }^{\circ} \mathrm{C}$ matches the physical property of concrete materials; and the calculated value of DYR was $11.87 \times 10^{-6} /{ }^{\circ} \mathrm{C}$, resulting in a relative error of $8.7 \%$ referring to the physical value of $13.0 \times 10^{-6} /{ }^{\circ} \mathrm{C}$ of the steel material. Finally, for the cross validation of D-TomoSAR and ground-based measurements, the motion parameters of a local area surrounding the NPSB Building (Figure 12) were estimated. Then, the geo-overlapped PSs motion time series from CSK were compared with the "CJDA" GPS observations in 2015 using the strategy of the closest spatiotemporal overlapping, indicating a 
consistent motion time series with the maximum dispersion of $4.7 \mathrm{~mm}$ and a standard deviation value of $2.5 \mathrm{~mm}$ (the precision of the Continuously Operating Reference Stations of GPS measurements in vertical, reported by the data provider), as illustrated in Figure 12. Compared to the distinct variation of GPS measurements, the D-TomoSAR derived motions are more robust owing to the fine modelling for motion contributions as well as the applied temporal filter for the noise mitigation in the time series estimation (e.g., the estimation of non-linear motion components).
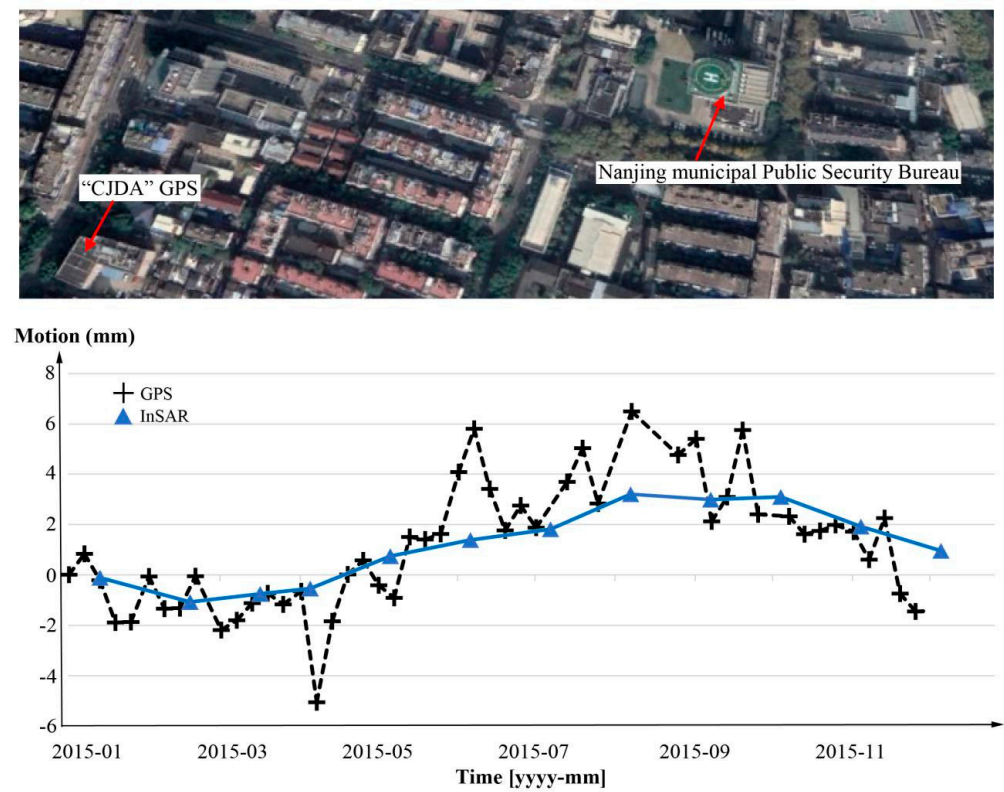

Figure 12. Validation of the D-TomoSAR derived result using the geo-overlapped GPS measurements (on courtesy of Google Earth).

\subsection{Tentative Performance Testing}

From a technology perspective, the extended D-TomoSAR can be a unique tool for preventive monitoring and health assessment of large-scale built structures using calculated motion products taking advantage of the availability of 2nd generation spaceborne SAR data (e.g., TSX/TDX and CSK) characterized by high-resolution and frequent revisit cycle. Generally, the spatiotemporal heterogeneity of motions (including thermodynamics) would be more destructive for the structural defect of built targets. The performance of aforementioned TSX/TDX and CSK SAR data in the structural monitoring were then tentatively tested using the indicators of spatial density and precision of motion measurements.

\subsubsection{Spatial Density of Extracted PSs Using the Amplitude Indicator}

Due to the high-resolution and the applied D-TomoSAR solution, the outline of large-scale built targets is recognizable by means of high-density PS measurements overlaid on the facade. Generally, the spatial density of PS measurements is essential to pinpoint structural motion anomalies. The performance of TSX/TDX and CSK data in PS extraction was tentatively evaluated. In the study, the amplitude dispersion with the threshold of 0.3 was applied for the PS candidate extraction. The conducted case studies of the NPSB Building, DYR Bridge and Ming Dynasty city wall indicated that the spatial density of PSs in TSX/TDX results are 2-7 folds higher than the CSK (Figures 3, 7 and 11). This phenomenon can be interpreted in two ways: first, the twin TSX/TDX and constellation CSK were applied for the InSAR time series analysis in this study (see Table 1). Compared with TSX/TDX (good overlap of common reflectivity spectra), the differences in radar signal level between CSK2 and CSK4 is quite significant, for e.g., it reaches up to $1.5 \mathrm{~dB}$ [32], resulting in a larger amplitude dispersion index and a lower detection of PS candidates in CSK results, apart from the potential consequence caused by 
the skipped procedure of radiometric calibration using the SkySense-InSAR software in this study. This phenomenon highlights the necessity of radiometric calibration for CSK data processing in PSInSAR or its extension D-TomoSAR procedures. Second, the imaging characteristics of aforementioned datasets are different, ascending of the former versus descending of the latter, results in differences in backscatters observed from structures which could also be modulated by other impacts such as different temporal acquisitions and revisit time intervals. Nonetheless, owing to the high spatial-resolution and the resultant PS density, CSK is also qualified for the structural motion monitoring, such as in experiments of [33].

\subsubsection{Motion Precision Using the Phase Indicator}

Note that, the 3D estimation capability of the two datasets in this study were comparable (height difference smaller than $1.0 \mathrm{~m}$ ), although a larger orbital tube of CSK missions tends to a better at height estimations theoretically. Except for this negligible factor, the sensitivity and/or precision of D-TomoSAR derived motions in spatiotemporal, recognized as an essential index in the structural instability monitoring, were then analyzed in order to facilitate high-resolution spaceborne InSAR data in the preventive monitoring of built structures. Taking the DYR Bridge as example, the corresponding experiment was carried out in the following manner. First, PS candidates were extracted using the uniform amplitude dispersion threshold of 0.3 on two datasets. Then, a PS point overlaid on the Pier 7 (stable condition due to the fixed bearing mounted [22]) was selected as the reference point (highlighted by the red-cross in Figure 13a,b). After that, motion time series on a PS immediately in the vicinity of the reference points (highlighted by the blue dot in Figure 13a,b) were estimated using the aforementioned two datasets, respectively. Considering the stable condition of Pier 7 as well as the negligible distance between the measured PS and the reference point, the motion variations (Figure $13 \mathrm{c}, \mathrm{d}$ ) indirectly reflect the precision of the motion estimation. Amplitude motion variations, -0.48 to $0 \mathrm{~mm}$ of TSX/TDX and -1.2 to $2.0 \mathrm{~mm}$ of CSK, again indicated a millimetric precision (within $2.0 \mathrm{~mm}$ ) of the motion estimation using aforementioned X-band SAR data.
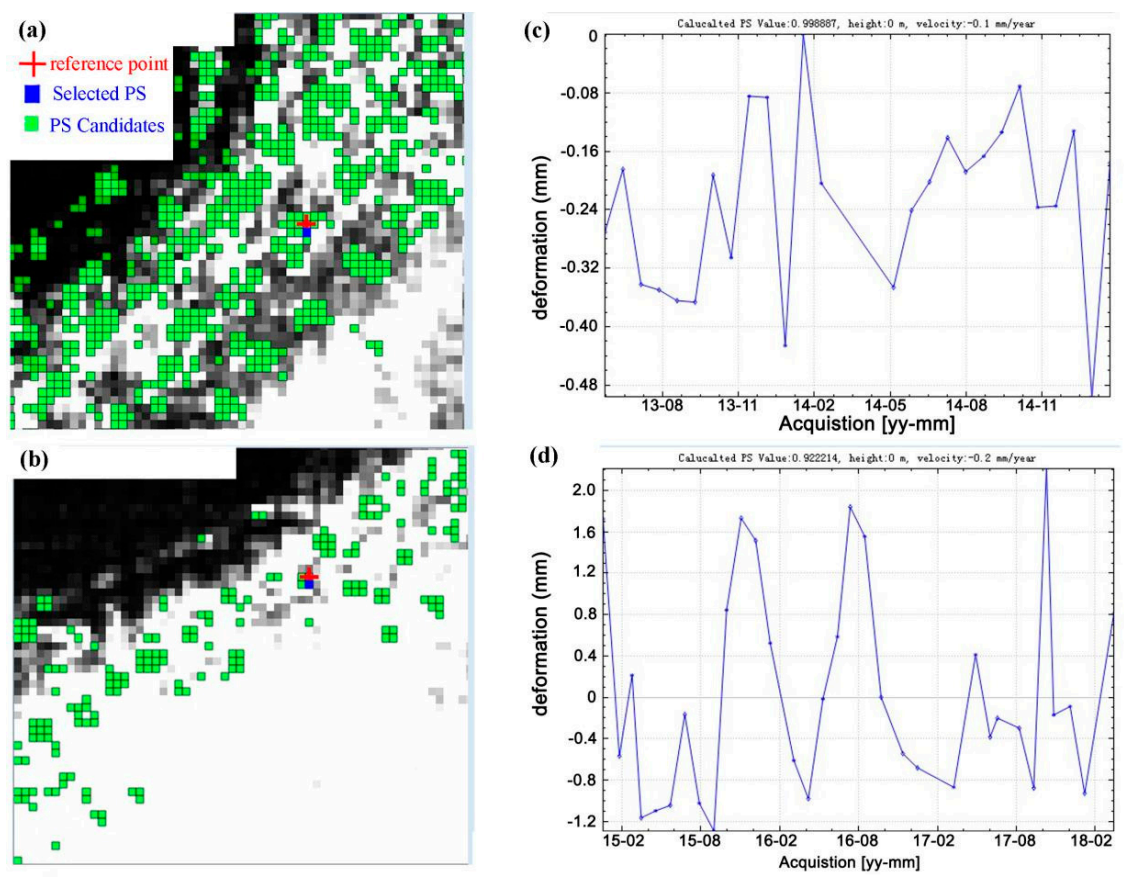

Figure 13. Uncertainty and/or precision of the motion estimation. $(\mathbf{a}, \mathbf{b})$ correspond to the PS candidates extracted from TSX/TDX and CSK, respectively; (c,d) are the calculated motion time series of selected PS candidates (marked by the blue dot) referring to their corresponding reference points (marked the red cross). 


\section{Conclusions}

Taking motions as the indicator, a two-tier network D-TomoSAR approach was exploited in this study to assess the potential and capability of current high-resolution spaceborne SAR data, including TSX and CSK missions, for monitoring structural instability of built structures in the urban landscape. Three representative built targets, including the NPSB Building, DYR Bridge and Ming Dynasty city walls were selected for detailed investigations. Implementation of the extended D-TomoSAR model (space-velocity-temperature) enhanced the spatial density of the measuring points and mitigated the unfavorable layover effects (prominent in high-resolution SAR images) at cost of computing efficiency that is generally acceptable for individual structures. Finally, motion contributions from velocity trends and material thermodynamics were estimated and separated with millimetric accuracy (up to 2-3 mm as validated), which is essential to detect actual motion anomalies relevant to structural defects and for the preventive diagnosis of those large-scale built structures. Studies indicated that X-band CSK data produce a better performance in the infrastructure monitoring, e.g., a better relative error $(8.7 \%)$ of the linear thermal expansion coefficient obtained in the case study of DYR Bridge versus the values of 13-14\% obtained using medium resolution C-band Sentinel-1 data [23]. Results also revealed that a long temporal span is essential to derive a robust estimation of thermal amplitudes, such as the applied CSK data with a 3-year observation span. Generally, a 2-year observation span could be the lower threshold to avoid the coupled ambiguity of linear velocity and thermal amplitude during parameter estimation; otherwise, it tended to be an inaccurate estimation of thermal amplitude, such as the derived result (Figure 3) by applying the 1.6-year observation span of TSX/TDX data. In addition, the extraction of DPSs generally obtains another $5-10 \%$ gain of PS measurements using the applied D-TomoSAR solution (formula [2,3]) [20,34], such as 5.9\% in the case of NPSB Building using TSX/TDX data, implying the effectiveness of the D-TomoSAR concept for the built structure monitoring.

From the point of surveillance on safety of built structures using high-resolution spaceborne SAR data, the performance of TSX/TDX and CSK were tentatively analyzed and tested using the indexes of spatial density and precision of motion measurements, assuming a guaranteed long observation span to avoid the coupled ambiguity of unknown parameters need to be estimated. Although more experiments would be needed (e.g., radiometric calibration prior to the PS candidate extraction) before conclusive inferences could be made, our pilot investigations indicated good performance of $X$-band high-resolution SAR data in monitoring the structural instability of built structures using the index of measuring point densities couple with the theoretical precision of estimated motions. Future studies should focus on the infrastructure risk mapping using Spotlight or Staring Spotlight spaceborne SAR data to test the performance of the extended D-TomoSAR tool using additional time-series motion indicators [35].

Author Contributions: F.C., W.Z., C.C. and P.M. conceived and designed the experiments; F.C., W.Z., and C.C. performed the InSAR data processing; F.C. and P.M. contributed InSAR results analysis and validation; F.C. wrote the paper.

Funding: This work was supported by the National Key Research and Development Program of China (No. 2016YFB0501502, No.2017YFE0134400) and National Natural Science Foundation of China (Grant No. 41771489).

Acknowledgments: The authors would like to thank the German Aerospace Center (DLR) for providing the TerraSAR/TanDEM-X SAR data in the frame of the AO TSX-Archive project (CAL3304). The SRTM DEM and Cosmo-SkyMed data provided by the United States Geological Survey (USGS) and e-GEOS, respectively, are also appreciated.

Conflicts of Interest: The authors declare no conflicts of interest.

\section{References}

1. Moschas, F.C.; Psimoulis, P.A.; Stiros, S.C. GPS/RTS data fusion to overcome signal deficiencies in certain bridge dynamic monitoring projects. Smart Struct. Syst. 2013, 12, 251-269. [CrossRef]

2. Gikas, V.; Sakellariou, M. Settlement analysis of the Mornos earth dam (Greece): Evidence from numerical modeling and geodetic monitoring. Eng. Struct. 2008, 30, 3074-3081. [CrossRef] 
3. Chan, T.H.T.; Yu, L.; Tam, H.Y.; Ni, Y.Q.; Liu, S.Y.; Chung, W.H.; Cheng, L.K. Fiber Bragg grating sensors for structural health monitoring of Tsing Ma bridge: Background and experimental observation. Eng. Struct. 2006, 28, 648-659. [CrossRef]

4. Chang, L.; Dollevoet, R.P.B.J.; Hanssen, R.F. Nationwide railway monitoring using satellite SAR interferometry. IEEE J-STARS 2017, 10, 596-604. [CrossRef]

5. Ferretti, A.; Prati, C.; Rocca, F. Nonlinear subsidence rate estimation using permanent scatterers in differential SAR interferometry. IEEE T Geosci. Remote. 2000, 38, 2202-2212. [CrossRef]

6. Tapete, D.; Fanti, R.; Cecchi, R.; Petrangeli, P.; Casagli, N. Satellite radar interferometry for monitoring and early-stage warning of structural instability in archaeological sites. J. Geophys. Eng. 2012, 9, S10-S25. [CrossRef]

7. Parcharidis, I.; Foumelis, M.; Benekos, G.; Kourkouli, P.; Stamatopoulos, C.; Stramondo, S. Time series synthetic aperture radar interferometry over the multispan cable-stayed Rio-Antirio Bridge (central Greece): Achievements and constraints. J. Appl. Remote. Sens. 2015, 9, 096082. [CrossRef]

8. Neokosmidis, S.; Elias, P.; Parcharidis, I.; Briole, P. Deformation estimation of an earth dam and its relation with local earthquakes, by exploiting multitemporal synthetic aperture radar interferometry: Mornos dam case (central Greece). J. Appl. Remote Sens. 2016, 10, 026010. [CrossRef]

9. Chang, L.; Hanssen, R.F. Detection of cavity migration and sinkhole risk using radar interferometric time series. Remote Sens. Environ. 2014, 147, 56-64. [CrossRef]

10. Tapete, D.; Morelli, S.; Fanti, R.; Casagli, N. Localising deformation along the elevation of linear structures: An experiment with space-borne InSAR and RTK GPS on the Roman Aqueducts in Rome, Italy. Appl. Geogr. 2015, 58, 65-83. [CrossRef]

11. Fornaro, G.; Serafino, F.; Reale, D. 4-D SAR imaging: The case study of Rome. IEEE Geosci. Remote Sen. 2010, 7, 236-240. [CrossRef]

12. Reale, D.; Fornaro, G.; Pauciullo, A.; Zhu, X.; Bamler, R. Tomographic imaging and monitoring of buildings with very high resolution SAR data. IEEE Geosci. Remote. Sen. 2011, 8, 661-665. [CrossRef]

13. Ma, P.; Lin, H.; Lan, H.; Chen, F. Multi-dimensional SAR tomography for monitoring the deformation of newly built concrete buildings. ISPRS J. Photogramm. 2015, 106, 118-128. [CrossRef]

14. Reale, D.; Fornaro, G.; Pauciullo, A. Extension of 4-D SAR imaging to the monitoring of thermally dilating scatterers. IEEE T Geosci. Remote 2013, 51, 5296-5306. [CrossRef]

15. Chen, F.; Wu, Y.; Zhang, Y.; Parcharidis, I.; Ma, P.; Xiao, R.; Xu, J.; Zhou, W.; Tang, P.; Foumelis, M. Surface motion and structural instability monitoring of Ming Dynasty City Walls by two-step Tomo-PSInSAR approach in Nanjing City, China. Remote Sens. 2017, 9, 371. [CrossRef]

16. Chen, F.; Guo, H.; Ma, P.; Lin, H.; Wang, C.; Ishwaran, N.; Hang, P. Radar interferometry offers new insights into threats to the Angkor site. Sci. Adv. 2017, 3, e1601284. [CrossRef]

17. Kang, J.; Wang, Y.; Körner, M.; Zhu, X.X. Robust object-based multipass InSAR deformation reconstruction. IEEE T Geosci. Remote 2017, 55, 4239-4251. [CrossRef]

18. Wang, Y.; Zhu, X.; Zeisl, B.; Pollefeys, M. Fusing meter-resolution 4-D InSAR point clouds and optical images for semantic urban infrastructure monitoring. IEEE T Geosci. Remote. 2017, 55, 14-26. [CrossRef]

19. Budillon, A.; Crosetto, M.; Johnsy, A.; Monserrat, O.; Krishnakumar, V.; Schirinzi, G. Comparison of Persistent Scatterer Interferometry and SAR Tomography Using Sentinel-1 in Urban Environment. Remote Sens. 2018, 10, 1986. [CrossRef]

20. Ma, P.; Lin, H. Robust detection of single and double persistent scatterers in urban built environments. IEEE T Geosc. Remote 2016, 54, 2124-2139. [CrossRef]

21. Lazecky, M.; Hlavacova, I.; Bakon, M.; Sousa, J.J.; Perissin, D.; Patricio, G. Bridge displacements monitoring using space-borne X-band SAR interferometry. IEEE J-STARS 2017, 10, 205-210. [CrossRef]

22. Huang, Q.; Crosetto, M.; Monserrat, O.; Crippa, B. Displacement monitoring and modelling of a high-speed railway bridge using C-band Sentinel-1 data. ISPRS J. Photogramm. 2017, 128, 204-211. [CrossRef]

23. Huang, Q.; Monserrat, O.; Crosetto, M.; Crippa, B.; Wang, Y.; Jiang, J.; Ding, Y. Displacement monitoring and health evaluation of two bridges using Sentinel-1 SAR images. Remote Sens. 2018, 10, 1714. [CrossRef]

24. Qin, X.; Liao, M.; Zhang, L.; Yang, M. Structural health and stability assessment of high-speed railways via thermal dilation mapping with time-series InSAR analysis. IEEE J-STARS 2017, 10, 2999-3010. [CrossRef] 
25. Viviani, F.; Pulella, A.; Lombardini, F. Multidimensional tomography with new generation VHR SAR data for urban monitoring. In Proceedings of the IEEE International Geoscience and Remote Sensing Symposium, Melbourne, Australia, 21-26 July 2013; pp. 81-84.

26. De Maio, A.; Fornaro, G.; Pauciullo, A. Detection of single scatterers in multidimensional SAR imaging. IEEE T Geosci. Remote 2009, 47, 2284-2297. [CrossRef]

27. Budillon, A.; Johnsy, A.; Schirinzi, G. A Fast support detector for superresolution localization of multiple scatterers in SAR tomography. IEEE J-STARS 2017, 10, 2768-2779. [CrossRef]

28. Budillon, A.; Johnsy, A.; Schirinzi, G. Extension of a fast GLRT algorithm to 5D SAR tomography of Urban areas. Remote Sens. 2017, 9, 844. [CrossRef]

29. Colesanti, C.; Ferretti, A.; Novali, F.; Prati, C.; Rocca, F. SAR monitoring of progressive and seasonal ground deformation using the permanent scatterers technique. IEEE T Geosci. Remote 2003, 41, 1685-1701. [CrossRef]

30. Monserrat, O.; Crosetto, M.; Cuevas, M.; Crippa, B. The thermal expansion component of persistent scatterer interferometry observations. IEEE T Geosci. Remote 2011, 8, 864-868. [CrossRef]

31. Fornaro, G.; Reale, D.; Serafino, F. Four-dimensional SAR imaging for height estimation and monitoring of single and double scatterers. IEEE T Geosci. Remote 2009, 47, 224-237. [CrossRef]

32. Baghdadi, N.; Hajj, M.E.; Dubois-Fernandez, P.; Zribi, M.; Belaud, G.; Cheviron, B. Signal level comparison between TerraSAR-X and Cosmo-SkyMed SAR sensors. IEEE Geosci. Remote S 2015, 12, 448-452. [CrossRef]

33. Crosetto, M.; Monserrat, O.; Cuevas- González, M.; Devanthéry, N.; Luzi, G.; Crippa, B. Measuring thermal expansion using X-band persistent scatterer interferometry. ISPRS J. Photogramm. 2015, 100, 84-91. [CrossRef]

34. Siddique, M.A.; Wegmüller, U.; Hajnsek, I.; Frey, O. Single-look SAR tomography as an add-on to PSI for improved deformation analysis in urban areas. IEEE T Geosc. Remote 2016, 54, 6119-6137. [CrossRef]

35. Pratesi, F.; Tapete, D.; Terenzi, G.; Ventisette, C.D.; Moretti, S. Rating health and stability of engineering structures via classification indexes of InSAR Persistent Scatterers. Int. J. Appl. Earth. Obs. 2015, 40, 81-90. [CrossRef]

(C) 2019 by the authors. Licensee MDPI, Basel, Switzerland. This article is an open access article distributed under the terms and conditions of the Creative Commons Attribution (CC BY) license (http://creativecommons.org/licenses/by/4.0/). 